\title{
Teaching Exploration on Dioptrics of Eye Based on Active Teaching Method in Higher Vocational Colleges
}

Kaidi Ma

Urumqi Vocational University, Urumqi 830022, Xinjiang, China. E-mail: 925pefect@sina.com

Abstract: With the development of information technology and the popularization of electronic products, more and more people are troubled by a metropia and binocular vision dysfunction. The public demand for visual service is increasingly urgent. How to cultivate people with solid theoretical knowledge and practical operation ability have become the fundamental goal of optometry vocational education. Based on this, taking "Refractive Examination" course as an example, this paper sorts out the basic content of the course and analyzes the existing problems in the teaching of the course with the combination of teaching, in order to adopt the positive teaching method to reform the classroom and practical teaching, so as to analyzes and summarizes the application of the teaching method in the course.

Keywords: Active Teaching Method; Optometry; Teaching Mode; Higher Vocational Education

\section{Introduction}

On June 5th, 2020, the National Health Commission officially issued the "White Paper on Eye Health in China", which formulated the national eye health plan for the "14th Five-Year Plan ", in order to further improved the eye health service system, promoted the high-quality development of ophthalmic medical services, and made efforts to meet the continuous improvement of people's eye health needs ${ }^{[1]}$. Nowadays, the social demand for optometry professionals is increasing year by year, and their abilities are more complex, skilled and innovative ${ }^{[2]}$. This further requires that the active teaching method be integrated into the teaching of optometry course.

Active teaching method has been applied in teaching in Europe and America, and formed a relatively perfect theoretical system and practical experience. Its essence is to mobilize students' learning enthusiasm and participate in it to acquire knowledge ${ }^{[3]}$. Through the overall analysis of the teaching materials, this paper aims to teach different types of teaching content, and put effective questions, brainstorming, group discussion, mind map, evaluation scale and other diversified teaching methods throughout the teaching process. Through the help of teachers and guidance of students in the course of "Refraction Examination", students can be trained to think independently, strengthen the ability of teamwork and self-study, so that they can experience the fun of exploration in learning, and really stimulate students' learning interest, thus improving the learning effectiveness.

\section{The present teaching situation of "Refraction Examination"}

"Refraction Examination" is a compulsory core course for the students majoring in optometry, with a total of 144 class hours, which are arranged in the second and third semester respectively. This course mainly describes the basic theory of optometry, introduces the imaging principles of various a metropia from the direction of geometric optics, and analyzes the

Copyright $(2020$ Kaidi Ma

doi: 10.18686/ahe.v4i10.2904

This is an open-access article distributed under the terms of the Creative Commons Attribution Non-Commercial License (http://creativecommons. org/licenses/by-nc/4.0/), which permits unrestricted non-commercial use, distribution, and reproduction in any medium, provided the original work is properly cited. 
physiological mechanism, clinical manifestations, examination methods and treatment methods of various ocular a metropia and binocular visual abnormalities from the perspective of ophthalmology medicine and visual health care. It not only includes the basic theory of optometry, but also the important professional skills operation of optometry visual function examination, as well as clinical case analysis and treatment. It is a course of professional theoretical knowledge and practical operation of skills. The course content involves many fields such as medicine, physics, materials science, machinery, etc. It is the core course of optometry major, featuring many professional definitions, term codes, legend analysis, and many practical operation requirements. Whether the course content can be mastered efficiently will directly affect the following professional learning and practical training, and it is also the key to cultivate the optometry talents with a solid theoretical foundation and a strong operational ability.

According to the teaching experience and students' feedback analysis, the problems existing in the traditional teaching process are summarized as follows:

(1) the content of the teaching material is professional, large span and abstract. The content of this course is formed by the intersection of physical optics knowledge and ophthalmic medicine knowledge. Most of the students have difficulty in systematic and in-depth theoretical study, which is difficult to keep up with and accept.

(2) the theory part mainly depends on multimedia courseware while the skill operation is mainly demonstrated and taught by classroom teachers. This kind of teaching method can't give full play to the students' initiative thinking enthusiasm, learning theory by rote and lacking of thinking. When doing practical training, it is difficult to combine theory learning with skill practice organically.

(3) In the past, teaching paid more attention to the implementation process of teachers' teaching objectives, while students' own learning objectives were not clear, learning motivation was insufficient and learning enthusiasm was not high.

(4) there is little interaction between teachers and students in the classroom, and the students also lack of discussion and communication with each other, which makes the whole classroom teaching process rigid and boring, and lacks a lively and dynamic learning atmosphere ${ }^{[4]}$.

(5) The course assessment process, evaluation method and evaluation content are relatively single, which can not accurately evaluate the overall mastery of students.

\section{Constructing course module and creating activity teaching mode}

According to the characteristics of the teaching materials, the course content is designed as a whole, and the knowledge system is divided into three modules: theory and understanding, technology and application, comprehensive analysis and innovation. According to the different modules of the course content, the corresponding optimized teaching methods are adopted to construct the course design scheme of "Refraction Examination" based on active teaching method.

First of all, the theory and understanding module mainly includes: basic concept, definition, mechanism, principle, etc.; the technology and application module mainly includes: visual function examination method, examination procedure, specific operation (mainly involves the third chapter: binocular visual function examination); comprehensive analysis and innovation module mainly includes: case analysis, diagnosis and treatment (mainly involving the fourth chapter: analysis and treatment of binocular visual dysfunction).

\section{The application of active teaching method in the course of refractive examination}

\subsection{Applying effective questioning to cultivate independent thinking}

In view of the theoretical knowledge module of the course, the method that can be more adopted is "effective questioning". In class, the core questions are the leading factor, such as the cause of myopia, symptoms and signs. First, the questions are thrown out, and then sufficient time is given for students to think independently. Finally, the students are named to express their opinions. This method can effectively avoid "roll call" that only the named students participate in thinking while others relax. By this way all students in the class can participate in independent thinking and achieve interactive teaching of effective questioning $^{[5]}$ For the complex and flexible parts, such as the teaching of a metropia correction principle, strabismus diplopic principle, abnormal convergence and dispersion function graphic analysis etc., this part of the content is more complex and 
abstract, and it is difficult to understand. By watching the video animation, students can fully internalize their understanding, and then "guided roll call questions" can be conducted to better guide thinking and understanding for students.

\subsection{Applying evaluation scale to improve learning autonomy}

According to the practical skills operation module, we should fully integrate theory and practice, design the practical skills evaluation scale to decompose the overall ability into various ability elements. Students can understand whether they have achieved the goal through self-assessment, so as to have expectations for success. If a student fails to pass one or more ability elements, the assessment must be accepted again. Students cannot also make independent inquiry through the ability list, but also improve their practical operation ability and practical training inquiry ability through group cooperation. The teacher gives full play to the leading role of guidance, inspiration and monitoring of the whole learning process to stimulate students' learning initiative, enthusiasm and creativity ${ }^{[6]}$.

\subsection{Applying mind map to improve the effect of active teaching}

For the comprehensive analysis and innovation module, the teacher takes the knowledge and skills that students should know after learning as the unit. For example, when learning the analysis and treatment of binocular vision examination, firstly guide the students to derive all the knowledge objectives and skill objectives of the course from the corresponding clinical questions of optometry, and let the students describe and display them with the logical mind map as the memory of the students in the learning process Links. Before learning each abnormal type, the teacher first raises questions based on clinical cases, such as what are the common binocular visual abnormalities, the diagnostic characteristics of each type of visual dysfunction, and how to carry out clinical analysis and treatment, which leads to a series of information needs for methods of identifying and dealing with visual impairment types, and requires students to find key data to judge and solve problems. It greatly stimulates students' interest in exploring knowledge, improves learning efficiency and realizes two-way exchange of knowledge ${ }^{[7]}$.

\section{Conclusion}

Through the overall analysis of "Refraction Examination" course content in higher vocational education, active teaching thinking can be throughout the teaching process. This teaching method focuses on the cultivation and assessment of students' independent thinking, autonomous learning ability, problem-solving ability and team cooperation ability. It not only increases the evaluation of students' subjective feelings and ability level and improves students' learning enthusiasm, but also makes up for the defects and deficiencies of traditional teaching mode, fundamentally improves the effectiveness of classroom teaching, and promotes the teaching reform of higher vocational education.

\section{References}

1. Yang Y. The overall myopia rate of children and adolescents in China was $53.6 \%$ according to the white paper on Chinese Eye Health issued by the health commission [EB/OL], 2020-06-06.

2. Bi Y. On the training of optometry talents under the background of intelligent technology. Electronic world 2019; 15(66-67).

3. $\mathrm{Hu} \mathrm{X}$. Research on the application of active teaching method in classroom teaching in vocational colleges. Yunnan Normal University; 2017.

4. Wang L. Misunderstandings and countermeasures of using multimedia courseware in medical teaching. Modern Medicine and Health $2011 ; 14$.

5. Li J, Yang C, Li Y, Mao J. The enlightenment of active teaching method to the teaching of coal mining. Journal of Higher Education 2019; 18(58-60).

6. Li Y. Research on the application of blended learning mode based on network teaching platform in colleges and universities. Nanchang University; 2014.

7. Hou Y, Tao N, Ying H, et al. Application of problem oriented evidence-based thinking teaching method in the teaching of optometry public health. Journal of Zhengzhou Railway Vocational and Technical College 2016; 04(77-80). 